\title{
Invited review: Antibiotic treatment of metritis in dairy cows: A systematic approach
}

\author{
P. Haimerl and W. Heuwieser ${ }^{1}$ \\ Clinic for Animal Reproduction, Faculty of Veterinary Medicine, Freie Universität Berlin, 14163 Berlin, Germany
}

\begin{abstract}
Acute puerperal metritis (APM) is an acute systemic illness with fever $\geq 39.5^{\circ} \mathrm{C}$ and signs of toxemia due to an infection of the uterus occurring within $21 \mathrm{~d}$ after parturition. Because of the infectious nature of APM, antibiotics are considered beneficial for its treatment. Each use of an antimicrobial drug, however, is associated with selective pressure for the emergence of resistant bacteria. Hence, there is a significant need to encourage prudent use of antibiotics and alternative therapies to antibiotics. Therefore, the objective of this study was to systematically review the current literature on treatment of APM. A comprehensive and systematic literature search was conducted utilizing the PubMed and $\mathrm{CAB}$ Abstracts databases to identify literature focusing on the antibiotic therapy of puerperal metritis in the cow. After application of specific exclusion criteria, 21 publications comprising 23 trials remained for final evaluation. Data extraction revealed that the majority of the studies $(\mathrm{n}=19)$ were attributable to the highest evidence level. Of 21 studies controlled, 11 had an untreated group and 3 a positive control group. The majority of the studies $(\mathrm{n}=17)$ applied ceftiofur for the treatment of APM. Concerning the efficacy of ceftiofur, 7 studies observed clinical improvement, whereas none found improved reproductive performance. Fewer than half of the studies $(\mathrm{n}=10)$ performed a bacteriological examination and only 4 implemented an antibiotic susceptibility test. Also, 3 studies (13.0\%) described a self-cure rate per se. Little attention was given to the issue of bacterial resistance $(\mathrm{n}=3)$, the need for reducing the application of antibiotics $(\mathrm{n}=2)$, or guidelines for prudent use of antibiotics $(n=1)$. Our findings demonstrate that implementation of bacteriological examinations, sensitivity testing, and determination of minimum inhibitory concentrations, as well as reporting and discussion of critical issues (e.g., self-cure rates, resistance, prudent drug use), were suboptimal. On the other hand, the quality of studies on the treatment of
\end{abstract}

Received June 7, 2014

Accepted July 29, 2014.

${ }^{1}$ Corresponding author: w.heuwieser@fu-berlin.de
APM was good, as indicated by evidence level 1. Nevertheless, more high-quality research considering self-cure rates is necessary to address critical issues related to APM and crucial to the dairy industry, such as resistance, prudent use of antibiotics, animal welfare, and cost-benefit ratios.

Key words: acute metritis, antibiotic treatment, systematic review, dairy cow

\section{INTRODUCTION}

\section{Definition and Diagnostic Challenges of Acute Puerperal Metritis}

Acute puerperal metritis (APM) is an acute systemic illness with fever $\geq 39.5^{\circ} \mathrm{C}$ and signs of toxemia due to an infection of the uterus, occurring within 21 d after parturition and characterized by an enlarged uterus and a watery red-brown fluid to viscous offwhite purulent uterine discharge, which often has a fetid odor (Sheldon et al., 2006, 2009). This definition is well accepted and has been used widely in recent research trials (Dubuc et al., 2011; McLaughlin et al., 2013; Sannmann et al., 2013b). Signs of systemic illness include decreased milk yield, dullness or other signs of toxemia, decreased DMI, elevated heart rate, and dehydration (Sheldon et al., 2008). When applying this definition, the reported incidence rate of APM reaches $20 \%$ (Sannmann et al., 2012), but incidence rates up to $40 \%$ were reported in older studies (Markusfeld, 1987). Due to its severe detrimental effects on reproductive performance and economics, APM is one of the most important postpartum diseases in dairy cows (Azawi, 2008; Overton and Fetrow, 2008; McLaughlin et al., 2013).

In both research and practice, the most utilized diagnostic criteria to detect a case of APM are an elevated rectal temperature $\left(\geq 39.5^{\circ} \mathrm{C}\right)$ and fetid, watery, red vaginal discharge (VD). A more recent systematic review regarding diagnostic methods for APM demonstrated that these 2 criteria were described in 39 (fever) and 21 (fetid VD) of 48 peer-reviewed research papers, respectively, addressing APM (Sannmann et al., 2012). Therefore, this definition has to be considered the best 
available reference standard. We have emphasized, however, that this definition is empirically based and requires refinement (Burfeind et al., 2014a) as there is no gold standard available (Sheldon et al., 2006). Although evidence exists that VD and body temperature are related (Palenik et al., 2009; Burfeind et al., 2014b) and might therefore be useful to differentiate metritic from healthy cows, both criteria are also imperfect and could introduce bias. Several factors that affect body temperature in dairy cows have been described (Burfeind et al., 2010) and we have proposed increasing the fever threshold to $40.0^{\circ} \mathrm{C}$ for heat-stressed cows (Burfeind et al., 2012). The sensorial assessment of odor of VD is subjective and error prone (Sannmann et al., 2013a).

The role and potential diagnostic use of acute phase proteins such as haptoglobin $(\mathbf{H p})$, serum amyloid A, and lipopolysaccharide have been comprehensively reviewed (Ceciliani et al., 2012). The most intensively researched acute phase protein in relation to uterine health in dairy cattle is Hp. Although an early study could not find an elevation of plasma $\mathrm{Hp}$ concentrations in metritic cows, except for the 3 most severely affected (Hirvonen et al., 1999), an elevated serum Hp concentration (1.06 to $1.90 \mathrm{~g} / \mathrm{L}$ ) has been shown to indicate an acute infectious process in dairy cows (Drillich et al., 2007; Huzzey et al., 2009). This was also supported by Sheldon et al. (2001), who found that acute phase protein concentrations were increased by bacterial contamination.

Reported sensitivities for the detection of metritis (50 to $79 \%$ ) and specificities (54 to 87\%), however, were only moderate (Huzzey et al., 2009; Dubuc et al., 2010; Burfeind et al., 2014b). Furthermore, Smith et al. (1998b) showed a steadily declining Hp concentration during a 5-d antibiotic treatment period. Test characteristic of elevated $\mathrm{Hp}$ concentrations might be confounded by the fact that $\mathrm{Hp}$ concentration can increase in the first week after calving due to calving-related tissue damage or fatty liver syndrome (Humblet et al., 2006; Silvestre et al., 2011). Therefore, Hp as an indicator of infection should be used with caution in the days following parturition (Humblet et al., 2006).

Considerable self-cure rates (i.e., 15.6 to $55.0 \%$ ) of cows diagnosed with APM using this definition have been reported (McLaughlin et al., 2012; Sannmann et al., 2013b). It is unclear whether low specificities of the diagnostic methods used to screen cows for APM with a consequently high prevalence of type I errors (i.e., high false-positive rate) might contribute to this self-cure rate.

After calving, the lumen of the uterus is usually contaminated by bacteria (Földi et al., 2006). Specific bacteria identified in the uterus of dairy cattle with
APM include Escherichia coli, Trueperella pyogenes, Fusobacterium necrophorum, Prevotella spp., and Bacteroides spp. (Miller et al., 2007; Bicalho et al., 2010; Santos et al., 2011). According to Noakes et al. (1991), Fusobacterium nucleatum and Proteus mirabilis are also frequently observed in puerperal uteri. Furthermore, nonbacteriological agents such as bovine herpesvirus 4 can cause endometrial tissue damage (Sheldon et al., 2009). Because of the infectious nature, implications for animal well-being, and a potentially life-threatening course, antibiotics are considered beneficial for the treatment of APM (Beagley et al., 2010; Machado et al., 2012).

\section{Antibiotic Treatment and Resistance}

For the treatment of metritis, antibiotics are given by the intrauterine route, systemically, or both (Malinowski et al., 2011). Antibiotics such as penicillin, third-generation cephalosporins, and ampicillin have been systemically administered for the treatment of cows with APM. Furthermore, dairy cows with APM have been treated with systemic penicillin or ampicillin administrations in conjunction with intrauterine instillations of oxytetracycline or ampicillin and cloxacillin (Nak et al., 2011). As shown about 3 decades ago for oxytetracycline and chloramphenicol, no significant differences were observed concerning the distribution of the drug between various tissues or between healthy and infected postpartum cows (Bretzlaff et al., 1983, 1988). The efficacy of these antibiotic drugs, however, is impossible to evaluate conclusively from the literature as different routes, doses, and products were applied and different examinations were performed on farms by farm or study personnel or veterinarians. It is well known that not all infections are eliminated following antibacterial treatment (Malinowski et al., 2011), and definitions of self-cure and cure rates differ widely (Drillich et al., 2001; Galvão et al., 2009).

Each use of an antimicrobial drug is inherently associated with selective pressure for the emergence of resistant bacteria, which stresses the importance of their prudent use (Fishman, 2006; Ozawa et al., 2012). Recently, several publications have demonstrated emerging antimicrobial resistance of zoonotic organisms in food animals worldwide and expressed a potential threat to public health (Tragesser et al., 2006; CVMP, 2009; Mann et al., 2011; Ozawa et al., 2012). It is obvious that increasing antibiotic resistance is associated with decreasing clinical efficacy and could exacerbate animal welfare and economic consequences. It is noteworthy that the antibiotic sensitivity of bacteria from uterine discharges has not been frequently tested (Malinowski et al., 2011). Hence, there is a significant need 
to encourage prudent use of antibiotics and alternative therapies to antibiotics (Ozawa et al., 2012). Such strategies involve selecting the most appropriate drug at its optimal dosage and duration to cure an infection while minimizing side effects and pressures for the selection of resistant strains (Fishman, 2006). Therefore, the objective of this study was to systematically review the current literature on antibiotic treatment of APM.

\section{Evidence-Based Medicine and the Role of Systematic Reviews}

In daily practice, veterinarians have to cope with an increasing amount of unstructured information (Smith, 1996; Eisend, 2004; Buchanan and Wooldridge, 2011). Nevertheless, they have to be able to critically judge information and to decide whether it can be adequately implemented for a given case. In this context, it is essential to base decisions on the latest and most sound scientific findings (Glasziou et al., 1998; Arlt and Heuwieser, 2005).

Reviews have long been used to summarize the body of literature on a given topic (Gordon et al., 2013). Especially in regard to the lack of time that today's doctors and scientists are confronted with (Vandeweerd et al., 2012), reviews can be very useful. Because systematic reviews follow a structured research protocol, they reduce sources of bias at all stages of the review (e.g., inclusion criteria for relevant literature, quality assessment of studies; Sargeant et al., 2006). When conducting a systematic review, it is important to consider the study designs of the articles as these determine the likelihood of bias (Karger et al., 2014). Consequently, studies concerning diagnostic tests should describe the methods of testing accurately to ensure reproducibility (Watson and Petrie, 2010). According to Kastelic (2006), randomized, controlled, double-blind studies represent the gold standard with regard to the evaluation of a certain treatment. However, there is a dearth of methodologically sound, rigorous, large-scale clinical studies in veterinary medicine, resulting in a lack of research results at the highest evidence level (Holmes and Cockcroft, 2004; Haimerl et al., 2012; Simoneit et al., 2012).

\section{Hypotheses}

As a working hypothesis, we assumed that the frequent usage of antibiotic drugs for the treatment of APM is at least partly based on studies showing methodological flaws. Therefore, we hypothesize that there is a considerable number of cases in which the application of antibiotics could be omitted or replaced by an alternative treatment. Specifically, we set out to test the following hypotheses: (1) Most of the studies are randomized and controlled; (2) fewer than $50 \%$ of the studies have an untreated control group; (3) fewer than $10 \%$ of the studies are blinded; (4) a bacteriological examination in the course of antibiotic treatment is conducted only by a minority of studies $(<50 \%)$; (5) antibiotic susceptibility testing is done in fewer than one-fourth of the studies; (6) the majority of those studies having performed an antibiotic susceptibility test use a disk diffusion test; (7) self-cure rates are assessed by fewer than $25 \%$ of the studies; (8) an MIC regarding the antibiotic applied is reported in fewer than $5 \%$ of the studies; and (9) only a minority of the studies address the issues of bacterial resistance and prudent drug use guidelines.

\section{MATERIALS AND METHODS}

A comprehensive and systematic literature search was conducted on May 23, 2014, utilizing the databases PubMed (http://www.pubmed.gov) and CAB Abstracts (http://ovidsp.tx.ovid.com/) to identify literature focusing on the antibiotic therapy of puerperal metritis in the cow. The subject heading "bovine metritis AND antibiotics" was used to find all trials on this topic written in English or German. Specific exclusion criteria were defined to exclude articles that did not describe experimental studies; for example, descriptive or in vitro studies. Conference proceedings and review articles were also excluded. Furthermore, articles not meeting the inclusion criteria because of incorrect indexation, and those not obtainable through the Internet, bibliographies, or interlending services were excluded as well. If multiple publications were retrieved that described the same trial, those containing the least information were regarded as doublets and excluded. Retrieval and management of references was performed by using Endnote (version X4 for Windows, Thomson Reuters, New York, NY).

The remaining publications were evaluated according to various evidence parameters using a checklist developed and pretested in a previous step (Table 1). Relevant criteria of the study design such as sample size, the involvement of control groups, blinding, and randomization were considered. Furthermore, information concerning the drug(s) applied, bacteriological investigations and antibiotic sensitivity testing, self-cure rates, and the critical discussion of certain aspects were documented in a spreadsheet. Frequency distributions were compiled using SPSS for Windows (version 22.0; SPSS Inc., Munich, Germany).

\section{RESULTS}

In total, 53 publications (Figure 1) were retrieved through systematic database literature search (PubMed: 
Table 1. Checklist used to evaluate publications on acute puerperal metritis in dairy cows considering the level of evidence

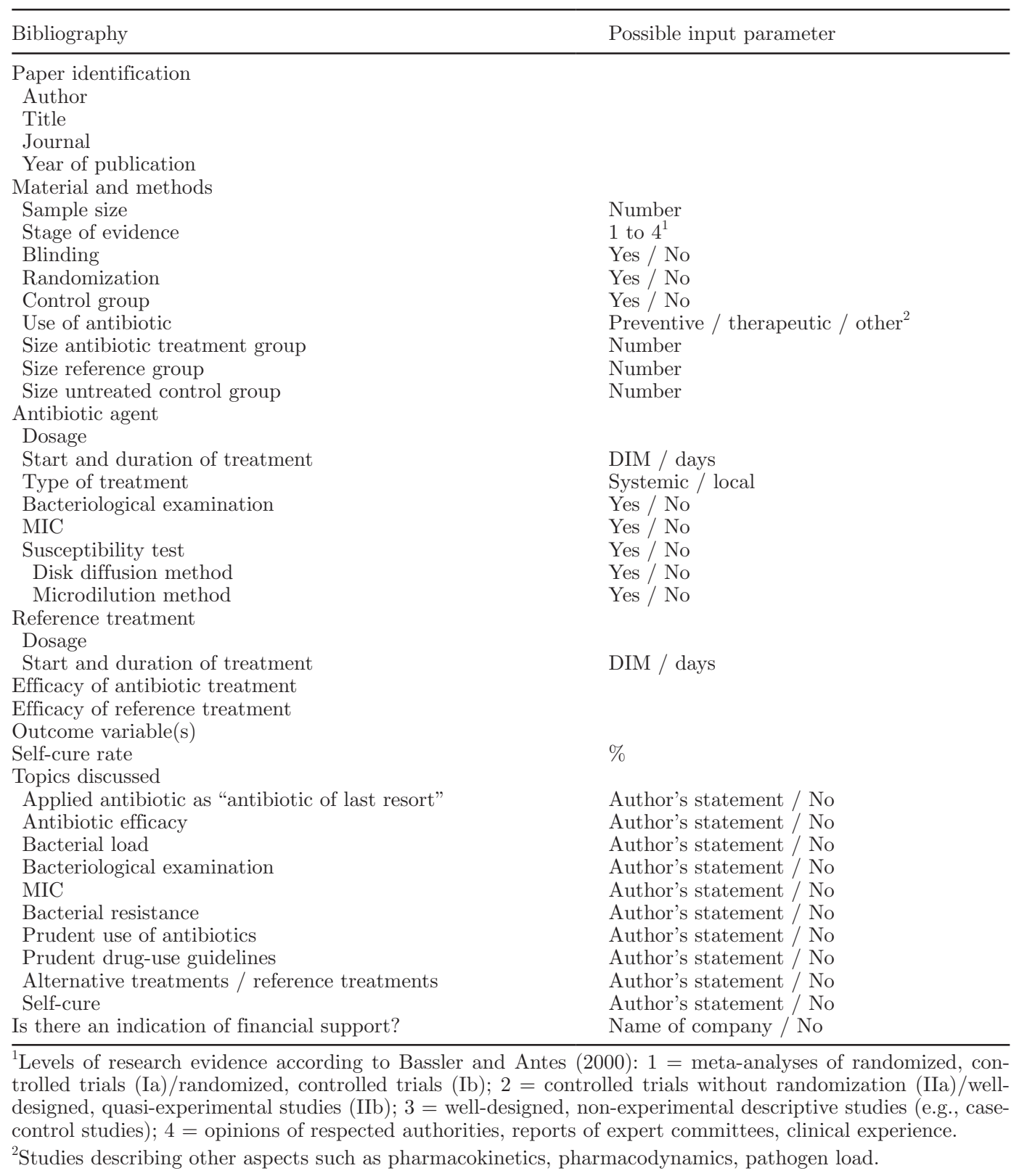

48; CAB: 4) and search by hand $(\mathrm{n}=1)$. According to the exclusion criteria, 31 indexed articles had to be excluded. In addition, 1 duplicate was excluded, resulting in 21 remaining publications that comprised 23 individual trials (Table 2). Fourteen of the 23 evaluated studies $(60.9 \%)$ had a sample size of $\geq 100$ (Table 3 ), whereas $6(26.1 \%)$ included fewer than 50 cows. According to the levels of evidence suggested by Bassler and Antes (2000), 19 of the studies (82.6\%) included were attributable to the highest evidence level (i.e., randomized, controlled studies; Figure 2). Two (8.7\%), 18 (78.3\%), and $21(91.3 \%)$ of the studies were fully blinded, ran- domized, and controlled, respectively (Table 4). Of those 21 studies controlled, 11 had an untreated group and 3 a positive control group (applying a treatment other than an antibiotic). The majority of the studies $(\mathrm{n}=13)$ pursued a therapeutic intervention and $5 \mathrm{a}$ preventive approach. Another 5 studies described other aspects such as pharmacokinetics, pharmacodynamics, or pathogen load. Concerning the antibiotic chosen for treatment, within the 23 studies assessed, 10 different antibiotic agents were applied. Ceftiofur and oxytetracycline were used in 17 and 5 trials, respectively. Efficacy of the antibiotic applied was specified in almost every 
study $(22 / 23)$. Concerning the efficacy of ceftiofur (the most frequent drug investigated, with 17 trials), 12 and 6 assessed effects on clinical and reproductive parameters, respectively. Although 7 studies observed clinical improvement, none found improved reproductive performance after an application of ceftiofur compared with the reference group. Concerning the second most commonly applied antibiotic agent (oxytetracycline), only 1 of 5 studies evaluated the effect on clinical parameters. The other 4 studies focused on residues in various tissues or in milk. Fewer than half of the studies $(\mathrm{n}=$ 10) performed a bacteriological examination and only 4 implemented an antibiotic susceptibility test. Regarding the method applied, 3 of those 4 used disk diffusion antibiotic sensitivity testing. An MIC of the antibiotic drug applied was specified in 3 studies (13.0\%). Also, 3 studies $(13.0 \%)$ described a self-cure rate per se. Another 4 publications (17.4\%) reported cure rates for the untreated control groups.

Efficacy of the applied antibiotic was discussed in $20(87.0 \%)$ of the publications. About two-thirds of the papers $(\mathrm{n}=15)$ referred to the actual or possible bacterial load, whereas 4 papers $(17.4 \%)$ discussed the issue of bacteriological examination. Minimum inhibitory concentrations were discussed in fewer than half of the studies $(\mathrm{n}=10)$. Little attention was given to the issue of bacterial resistance $(\mathrm{n}=3)$, the need to reduce the application of antibiotics $(n=2)$, or guidelines for prudent use of antibiotics $(\mathrm{n}=1)$. The topic "antibiotics of last resort" was addressed in 3 of 23 papers. More than one-third $(\mathrm{n}=8)$ of the studies referred to implemented or possible alternatives, whereas 8 of 23 studies (34.8\%) discussed the possibility of a self-cure. A reference to the funding institution could be found in the majority of the papers $(\mathrm{n}=12)$.

\section{DISCUSSION}

The literature search with the subject heading "bovine metritis AND antibiotics" in 2 well-recognized databases (i.e., PubMed and $\mathrm{CAB}$ ) revealed only 52 publications. This result clearly shows a dearth of research on a highly prevalent topic, part of which (i.e., antibiotic resistance) has been recognized worldwide as a top public health challenge in the 21st century (Machado et al., 2014). This finding is in accordance with the outcome of the study conducted by Sannmann et al. (2012), who identified 48 publications related to APM in general. A similar shortage of research results has been described for other relevant veterinary topics by various authors (Silverlås et al., 2009; Haimerl et al., 2012; van Knegsel et al., 2013; Karger et al., 2014). To ensure that we did not miss relevant literature based on the search strategy, we additionally searched the chosen databases using the broader subject heading "metritis AND dairy cow." Reviewing the retrieved literature (PubMed: 288; CAB: 67), however, revealed that the original search strategy had uncovered all relevant publications on antibiotic therapy of puerperal metritis in the cow. Nevertheless, we are aware that every literature search has its limitations. Selective inclusion by databases, various modes and different speeds of indexation, and partly incorrect indexation make it impossible to obtain every publication on a certain topic at a given time. Thus, we assume that every systematic review and meta-analysis runs the risk of overlooking studies with potential relevance.

While compiling the literature, we learned that 7 of the 52 publications found were not obtainable via the Internet. One could argue that we should have contacted the authors of publications not available online or through the interlibrary lending system. However, implementing the concepts of evidence-based veterinary medicine in practice requires obtaining high-quality scientific information in an adequate time period and with reasonable effort (Smith, 1996). Therefore, contacting the authors of publications not accessible online does not represent a practitioner's or researcher's reality.

Considering the current broad coverage of the Internet and future rapid technological advances (Nault and Baker, 2011), we postulate an online availability of every published paper. Otherwise, accessibility is not guaranteed.

In 6 of the 23 trials, the total sample size was $<50$ cows; however, 11 trials included $>200$ animals. More important than the absolute number of animals included is whether the sample size of each group was large enough to test the research hypotheses proposed. Only 6 of the 23 studies, however, described an a priori sample size calculation and 1 described a subsequent sample size calculation for the study. Therefore, a final evaluation of the adequacy of the sample size is not possible.

Surprisingly, assessment of the evidence level according to the stages suggested by Bassler and Antes (2000) revealed 19 publications $(82.6 \%)$ attributable to the highest level. This is in contrast to several systematic literature evaluations on other veterinary topics that uncovered serious methodological flaws and a greater proportion of publications with lower evidence levels (Olivry and Mueller, 2003; Gordon et al., 2013; Haimerl et al., 2013; Karger et al., 2014). Besides the evidence level, accuracy and comprehensiveness of reporting are important indicators for the quality of a publication. For example, serious weaknesses concerning the reporting of the diagnostic methods to identify cows with APM (Sannmann et al., 2012) and reproductive tract disease (de Boer et al., 2014) have been described. 


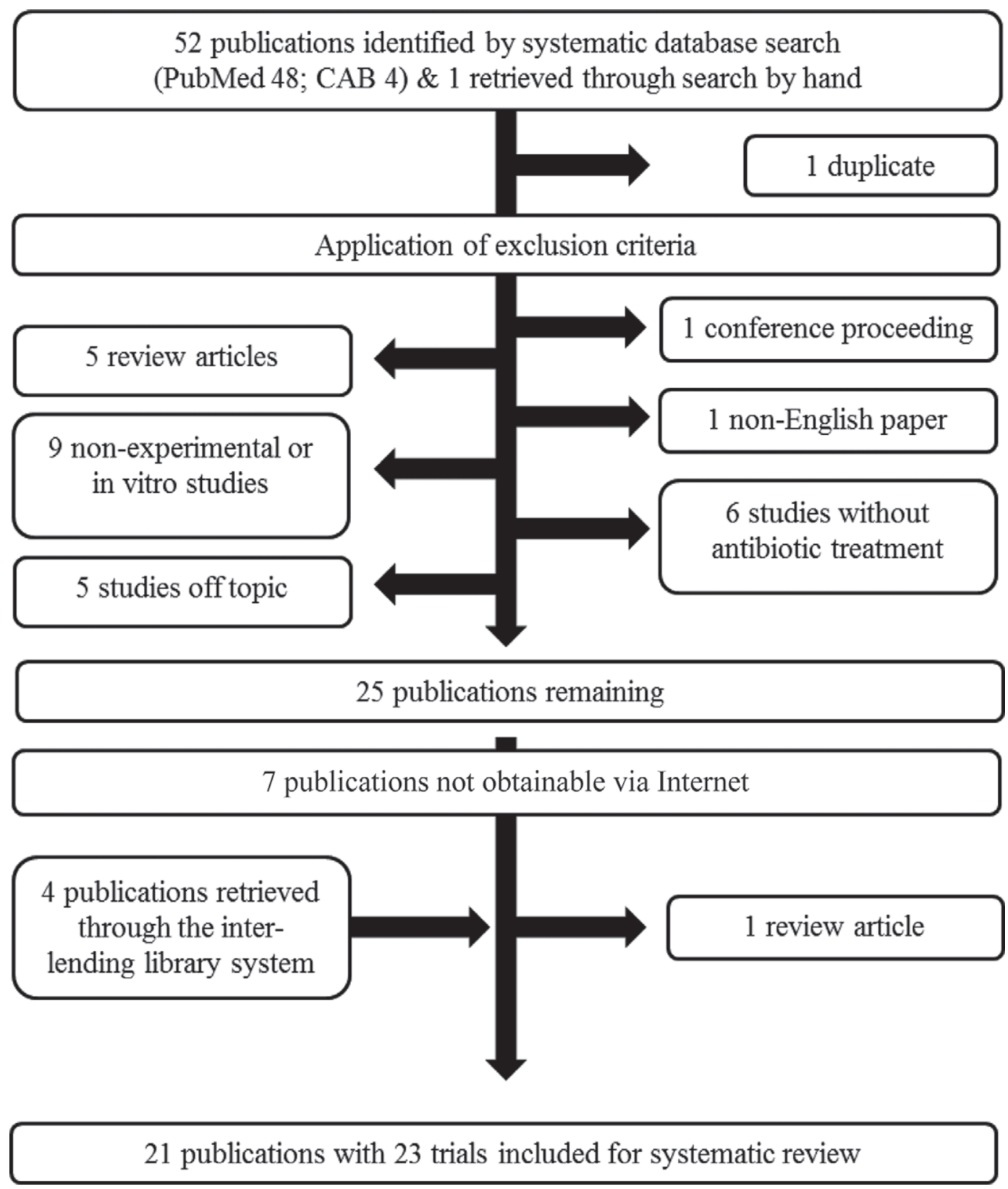

Figure 1. Publications on antibiotic treatment of acute puerperal metritis in dairy cows retrieved and systematically evaluated after applying preset exclusion criteria.

Concerning the antibiotic drug chosen for treatment, data extraction revealed that more than two-thirds $(73.9 \%)$ of the studies used ceftiofur, a third-generation cephalosporin approved for the treatment of APM, pneumonia, and lameness in cattle. This result, however, is not surprising because Sannmann et al. (2012) stated that ceftiofur is widely used in research trials. In human medicine, third-generation cephalosporins are valued for treating serious or life-threatening infections. Therefore, the use of ceftiofur in dairy cows is seen as a potential threat to its ability to cure a range of life-threatening infections in people. Specifically, it has been hypothesized that therapeutic use of ceftiofur in food-producing animals may be responsible for the emergence of ceftriaxone resistance (Allen and Poppe, 2002). Only 3 papers, however, addressed the critical issue of "antibiotics of last resort." Despite steadily increasing antimicrobial resistance (Ozawa et al., 2012), fewer than half of the investigated studies $(\mathrm{n}=10)$ performed a bacteriological examination and even fewer 
Table 2. Research articles $(n=21)$ on the antibiotic therapy of puerperal metritis in dairy cows chosen for systematic evaluation

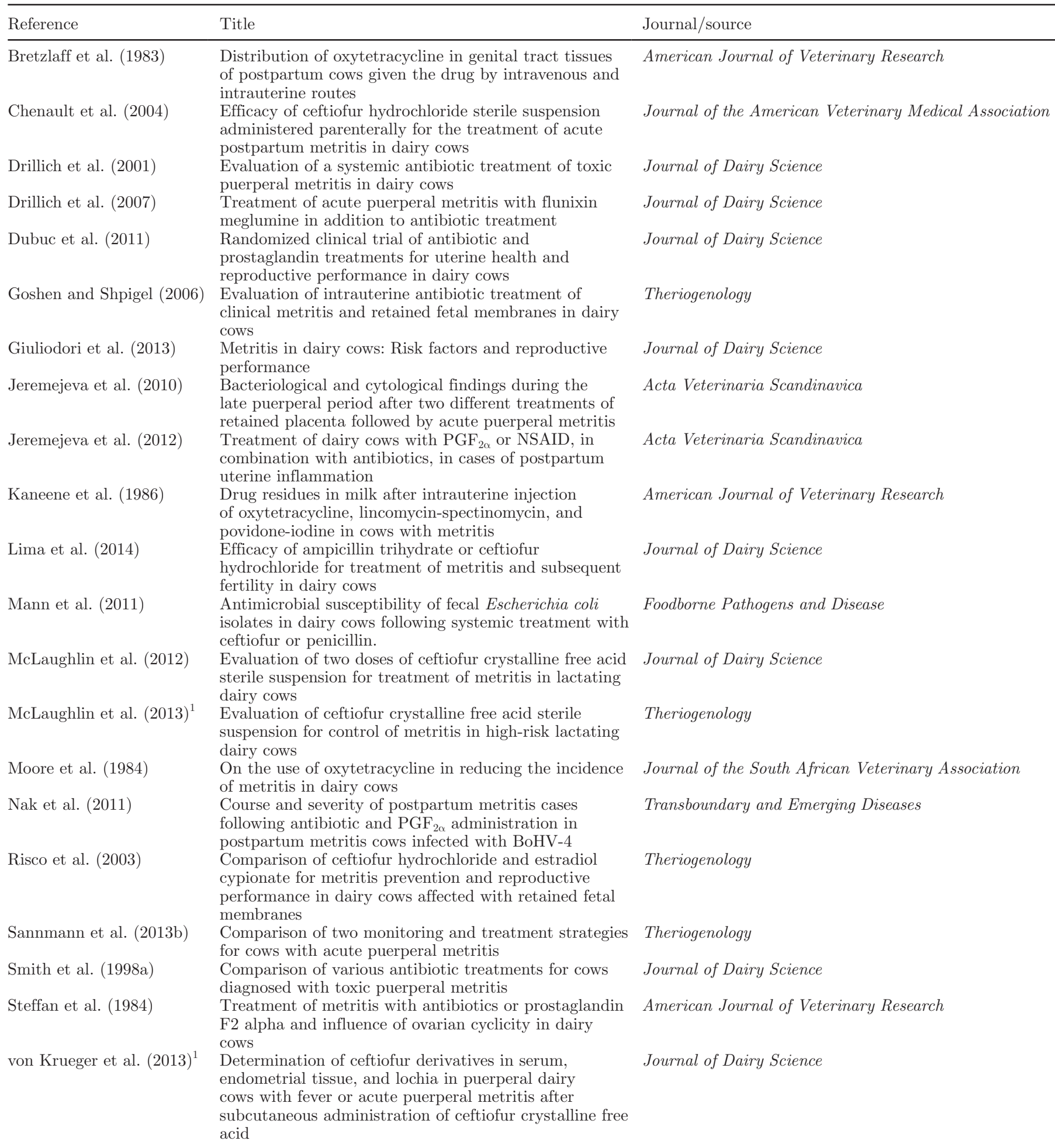

${ }^{1}$ Journal articles comprising 2 experiments.

$(\mathrm{n}=4)$ an antibiotic susceptibility test. Sound diagnostics to identify the etiology of infections, however, are an essential prerequisite for prudent use of antibiotics and to prevent emergence and further spread of antibiotic resistance (Fishman, 2006). Furthermore, only 4 and 3 of 23 studies discussed issues of bacteriologi- 
Table 3. Sample sizes of the assessed studies $(n=23)$ considering study group

\begin{tabular}{lrcc}
\hline & \multicolumn{3}{c}{ Sample size } \\
\cline { 2 - 4 } Group & $<100$ & $\geq 100$ & Not specified \\
\hline Total $(\mathrm{n}=23)$ & 9 & 14 & 0 \\
Antibiotic group $(\mathrm{n}=23)$ & 13 & 9 & 1 \\
Untreated control $(\mathrm{n}=17)$ & 9 & 7 & 1 \\
Reference group $(\mathrm{n}=6)$ & 4 & 2 & 0 \\
\hline
\end{tabular}

cal examination and bacterial resistance, respectively. With regard to the different objectives addressed by the different studies, one might argue whether every type of study should be obligated to discuss the issue of bacterial resistance in depth. However, due to the multi-layer nature of this problem (i.e., decreasing efficacy of antimicrobials, major public health concern, perception by the public, and potential consequences for the industry), we believe that at least every current study on antibiotics should mention this issue. Concerning the method of antibiotic sensitivity testing, 3 of the 4 studies conducting sensitivity testing used a disk diffusion test. Despite the fact that the disk diffusion method is widely used in routine clinical laboratories and in some research laboratories, unreliable test results have been shown for different bacteria species, such as Campylobacter spp. (Lehtopolku et al., 2012). Major disadvantages of the disk diffusion test are its qualitative nature (i.e., susceptible, intermediate, or resistant) rather than providing a MIC (Jorgensen and Ferraro, 2009) and the lack of mechanization or automation of the test. According to Rocksin et al. (2007), the broth microdilution method is considered the method of choice for in vitro susceptibility testing of bacterial pathogens, which also provides data concerning the MIC (Pierce-Hendry and Dennis, 2010). Irrespective of the test applied, appropriate breakpoints are a prerequisite to differentiate susceptible from resistant bacteria and to guide a therapeutic approach based on clinical breakpoints (Supré et al., 2014). However, microbiological breakpoints derived from the MIC do not necessarily equate to clinical breakpoints (Dalhoff et al., 2009). In addition, as different research groups use different breakpoints, data on susceptibility are rarely comparable (Supré et al., 2014).

Surprisingly, in spite of the frequent usage of ceftiofur $(\mathrm{n}=17)$, none of those studies provided evidence of improved reproductive performance after treatment compared with a reference group. Although clinical improvement, as demonstrated in 7 studies, is important concerning animal welfare and animal health, it is reproductive performance that has a long-term effect on profitability because it affects milk production, reproductive culling rates, and animal sales (Plaizier et al., 1998). Furthermore, the different approaches (therapeutic, preventive, or those focusing on pharmacokinetics, pharmacodynamics, or pathogen load) decrease comparability of the studies and create a challenge for synoptically assessing the efficacy of a certain treatment.

It is well known that the MIC of the pathogen is relevant for selection of an appropriate antibiotic drug (Sheldon et al., 2004). None of the studies included in this systematic review determined an MIC for relevant



Figure 2. Levels of evidence of 23 studies addressing antibiotic treatment of acute puerperal metritis in dairy cows. 
Table 4. Results of data extraction considering quality criteria and topics discussed of 23 trials

\begin{tabular}{lrr}
\hline Criterion & Yes & No \\
\hline Materials and Methods & & \\
Blinding' $^{1}$ & 2 & 16 \\
Randomization & 18 & 5 \\
Control group, overall & 21 & 2 \\
Control group, untreated & 17 & 6 \\
Reference group & 11 & 12 \\
Sample size calculation & 7 & 16 \\
Efficacy of antibiotic reported & 22 & 1 \\
Bacteriological examination & 10 & 3 \\
MIC & 4 & 20 \\
Antibiotic susceptibility testing & 3 & 19 \\
Self-cure rate reported & 12 & 20 \\
Financial support indicated & & 11 \\
Topics discussed & 3 & 20 \\
Applied antibiotic as "antibiotic of last resort" & 3 \\
Antibiotic efficacy & 20 & 8 \\
Bacterial load & 15 & 49 \\
Bacteriological examination & 4 & 13 \\
MIC & 10 & 20 \\
Bacterial resistance & 3 & 21 \\
Prudent use of antibiotics & 2 & 22 \\
Prudent drug-use guidelines & 1 & 15 \\
Alternative treatments/reference treatments & 8 & 15 \\
Self-cure & 8 & \\
${ }^{1}$ Five studies partly blinded. & & \\
${ }^{2}$ Including 3 studies with a reference group treated with drugs other than antibiotics. & \\
\end{tabular}

pathogens. Three studies specified an MIC for the chosen antibiotic drug and certain pathogens based on findings of other researchers. Interestingly, all 3 authors referred to one paper by Sheldon et al. (2004). Nevertheless, a discussion of MIC was included in more than one-third of the studies $(\mathrm{n}=9)$.

The majority of the studies $(n=19)$ discussed the efficacy of the antibiotic applied based on clinical parameters such as cure rates as defined by fever, discharge, and, in some cases, Hp concentrations ( $\mathrm{n}=$ 3) or considering reproductive performance parameters. Only 1 of the studies, however, evaluated bacteriological cure rates as frequently conducted in mastitis research (Kalmus et al., 2014). A total of 7 studies mentioned self-cure rates $(\mathrm{n}=3)$ or reported cure rates for their untreated control groups $(\mathrm{n}=4)$. The average cure rate without any treatment of those 7 studies was $36.9 \%$ (minimum: 16\%, maximum: $62 \%$ ). A quantitative representation summarizing clinical cure rates from different studies by means of a forest plot as used in meta-analysis (Barker and Carter, 2005) was not possible because the parameters to define clinical cure were inconsistent.

Ceftiofur has been approved for the treatment of APM in the United States and Europe, specifically for a treatment for 5 consecutive days. Management practices associated with antibiotic use on dairy farms vary considerably and compliance is suboptimal (Sawant et al., 2005). Furthermore, anecdotal evidence from the field suggests that, on average, only 2 to 3 treatments are administered for treatment of feverish metritis. It is unknown if a shortened time above MIC causes suboptimal cure rates, poses a risk for subclinical endometritis, or reduces reproductive performance (Witte et al., 2011). Furthermore, an abbreviated treatment $(<3$ d) can be considered off-label drug use and, due to suboptimal pharmacokinetics, exacerbate emergence of resistant bacteria.

Only 2 papers referred to the need to reduce the application of antibiotics and only 1 to the implementation of existing guidelines concerning prudent antibiotic drug use for the treatment of APM. Certainly, one explanation for this finding is the age of the studies included. The majority of the studies $(n=18)$ were published after the year 2000. On the one hand, public concern regarding the emergence of resistance has emerged more broadly in the last 10 years. Therefore, it is plausible that a significant part of the studies evaluated did not address prudent antibiotic drug use or resistance. On the other hand, the World Health Organisation (OIE) demanded prudent use of antibiotic agents in 1997, followed by the introduction of various guidelines (Teale and Moulin, 2012). Therefore, critical consideration of the topic of bacterial resistance might have been expected by those 18 studies conducted after the year 2000. This was true, however, in only 3 cases.

As pointed out by Ozawa et al. (2012), antimicrobial resistance is steadily increasing, which might lead to 
decreased clinical efficacy. However, it seems unlikely that new antibiotic drugs will become available soon. Absurdly, the rapid advance of resistance and the consequent need to use these drugs sparingly has convinced pharmaceutical companies that antibiotics are not worth the investment (McKenna, 2013). Hence, there is a significant need to encourage the use of alternative therapies. Only 8 of 23 studies, however, discussed implemented or possible alternatives to antibiotics. Six of the studies actually determined the efficacy of a drug other than an antibiotic. However, 3 of those (Drillich et al., 2007; Nak et al., 2011; Jeremejeva et al., 2012) applied a treatment consisting of a prostaglandin $\mathrm{F}_{2 \alpha}$ analog or flunixin in combination with an antibiotic drug and hence did not aim to reduce the amount of applied antibiotics. According to Malinowski et al. (2011), possible alternatives to the treatment of APM include prostaglandin $\mathrm{F}_{2 \alpha}$ analogs and nonsteroidal antiinflammatory drugs (NSAID). The efficacy of NSAID (e.g., flunixin meglumine) for the treatment of APM has not yet been demonstrated, and the need for further research has been described by Drillich et al. (2007). Most recently, vaccination against the predominant bacteria to prevent postpartum uterine diseases has been described as another promising alternative to an antibiotic treatment (Machado et al., 2014). Finally, there is some evidence that suggests that leaving early APM cows untreated for $2 \mathrm{~d}$ is a justified approach to restrict antibiotic treatment without negative effects (Sannmann et al., 2013b). Considerable self-cure rates of 15.5 and $55.3 \%$ have been calculated within the first $5 \mathrm{~d}$ and $14 \mathrm{~d}$ postpartum, respectively (McLaughlin et al., 2012; Sannmann et al., 2013b). Despite these interesting findings, only 8 of the 23 studies discussed the possibility of a self-cure. Also, 7 studies calculated self-cure rates or reported cure rates for their untreated control groups. The latter studies, however, were not identical to those studies discussing the possibility of a self-cure, which means that some of the studies discussing a possible self-cure rate did not report one, and vice versa.

It is noteworthy that the majority of papers $(\mathrm{n}=$ 12) included a reference to financial support. Financial relationships among industry, scientific investigators, and academic institutions are widespread, and conflicts of interest arising from these ties can influence biomedical research in important ways (Bekelman et al., 2003). Many authors have expressed concern about financial interests threatening not only research integrity but also independence in decision making, communication between researchers, public trust in the research establishment, and patient safety (Okike et al., 2008). Furthermore, it has been pointed out that studies sponsored by pharmaceutical companies are approximately
4 times more likely to have outcomes favoring the sponsor's product than studies with other funding (Lexchin et al., 2003). This might be due to biased choices of comparator drugs (seriously inferior or at unusually low doses), or to decisions not to publish less favorable results, or both. Needless to say, financial conflicts of interest threaten patient care, especially when new drugs are promoted on the basis of flawed research, and taint medical information (Okike et al., 2008). Nevertheless, according to Blumenthal (1994), some evidence suggests that academic-industry relationships may have scientific and educational benefits in addition to their health and economic payoffs. Life science faculty with industrial research support publish more peer-reviewed articles (controlling for level of support from all sources) than faculty without industry funding. Furthermore, it is obvious that a considerable amount of data must have been generated by pharmaceutical companies for their submissions to regulatory bodies. Although these studies are usually of very high standard, the data are not readily accessible.

In summary, through systematic literature assessment, we confirmed the majority of our hypotheses (i.e., nos. 1, 3, 4, 5, 6, 7, and 9). On the other hand, we had to reject our hypotheses that fewer than $50 \%$ of the studies have an untreated control group (no. 2) and that an MIC is reported in fewer than $5 \%$ of the studies (no. 8).

\section{SUMMARY AND CONCLUSIONS}

Antibiotic resistance worldwide is recognized already as a top public health challenge in the 21st century (Machado et al., 2014). While conducting this systematic review with the objective to elucidate the evidence behind antibiotic treatment and to evaluate indicators of cure after antibiotic treatment of APM in dairy cattle, particularly considering ceftiofur, certain limitations but also certain strengths of the available literature became obvious. It has been demonstrated that the diagnostic value of methods used to identify APM is weak (Sannmann et al., 2012) and a gold standard does not exist (Sheldon et al., 2006), which makes refinement of diagnostic procedures difficult. Considering the growing concern regarding the potential impact of extensive use of antibiotics in food animals, including later-generation cephalosporins (Dolejska et al., 2011), potential type I errors (i.e., treatment of a healthy animal) are particularly critical. The magnitude of such errors, however, is not available because of the lack of a gold standard. Furthermore, reported cure rates for treatment groups can be confounded by low sensitivities of the diagnostic tests employed. Our findings demonstrate that implementation of bacteriological 
examinations, sensitivity testing, and determination of MIC, as well as reporting and discussion of critical issues (e.g., self-cure rates, resistance, prudent drug use), was suboptimal. On the other hand, quality of studies on the treatment of APM was surprisingly good, as indicated by evidence level 1 (i.e., randomized, controlled trials) in 19 of 23 studies. It is also noteworthy that one antibiotic drug (ceftiofur) was predominantly used (17 of 23 studies) for the treatment of APM and can be considered well researched. Efficacy of this antibiotic drug concerning clinical and reproductive parameters was demonstrated by 13 (7 showed improvement) and 6 (0 showed improvement) studies, respectively. Nevertheless, more high-quality research considering self-cure rates is necessary to address critical issues related to APM and crucial to the dairy industry such as accuracy of diagnostic methods, resistance, prudent use of antibiotics, animal welfare, and cost-benefit ratios.

\section{REFERENCES}

Allen, K. J., and C. Poppe. 2002. Occurrence and characterization of resistance to extended-spectrum cephalosporins mediated by betalactamase CMY-2 in Salmonella isolated from food-producing animals in Canada. Can. J. Vet. Res. 66:137-144.

Arlt, S., and W. Heuwieser. 2005. Evidence-based veterinary medicine. Dtsch. Tierarztl. Wochenschr. 112:146-148.

Azawi, O. I. 2008. Postpartum uterine infection in cattle. Anim. Reprod. Sci. 105:187-208.

Barker, F. G., 2nd, and B. S. Carter. 2005. Synthesizing medical evidence: Systematic reviews and metaanalyses. Neurosurg. Focus 19:E5.

Bassler, D., and G. Antes. 2000. Wie erhalte ich Antworten auf meine Fragen? Pages 89-97 in Lehrbuch Evidenzbasierte Medizin in Klinik und Praxis. R. Kunz, G. Ollenschläger, H. Raspe, G. Jonitz, and F. W. H. Kolkmann, ed. Dt. Ärzte-Verlag, Köln, Germany.

Beagley, J. C., K. J. Whitman, K. E. Baptiste, and J. Scherzer. 2010. Physiology and treatment of retained fetal membranes in cattle. J. Vet. Intern. Med. 24:261-268.

Bekelman, J. E., Y. Li, and C. P. Gross. 2003. Scope and impact of financial conflicts of interest in biomedical research: A systematic review. JAMA 289:454-465.

Bicalho, R. C., V. S. Machado, M. L. Bicalho, R. O. Gilbert, A. G. Teixeira, L. S. Caixeta, and R. V. Pereira. 2010. Molecular and epidemiological characterization of bovine intrauterine Escherichia coli. J. Dairy Sci. 93:5818-5830.

Blumenthal, D. 1994. Growing pains for new academic/industry relationships. Health Aff. (Millwood) 13:176-193.

Bretzlaff, K. N., R. S. Ott, G. D. Koritz, R. F. Bevill, B. K. Gustafsson, and L. E. Davis. 1983. Distribution of oxytetracycline in genital tract tissues of postpartum cows given the drug by intravenous and intrauterine routes. Am. J. Vet. Res. 44:764-769.

Bretzlaff, K. N., R. S. Ott, G. D. Koritz, T. F. Lock, C. A. Neff-Davis, B. K. Gustafsson, and L. E. Davis. 1988. Distribution of chloramphenicol in the genital tract of postpartum cows. Am. J. Vet. Res. 49:914-917.

Buchanan, R. A., and A. A. Wooldridge. 2011. Staying current by searching the veterinary literature. J. Vet. Med. Educ. 38:10-15.

Burfeind, O., M. Bruins, A. Bos, I. Sannmann, R. Voigtsberger, and W. Heuwieser. 2014a. Diagnosis of acute postpartum metritis by electronic nose device analysis of vaginal discharge. Theriogenology 82:64-70.

Burfeind, O., I. Sannmann, R. Voigtsberger, and W. Heuwieser. 2014b. Receiver operating characteristic curve analysis to determine the diagnostic performance of serum haptoglobin concentration for the diagnosis of acute puerperal metritis in dairy cows. Anim. Reprod. Sci. http://dx.doi.org/10.1016/j.anireprosci.2014.07.020.

Burfeind, O., V. S. Suthar, and W. Heuwieser. 2012. Effect of heat stress on body temperature in healthy early postpartum dairy cows. Theriogenology 78:2031-2038.

Burfeind, O., M. A. von Keyserlingk, D. M. Weary, D. M. Veira, and W. Heuwieser. 2010. Short communication: Repeatability of measures of rectal temperature in dairy cows. J. Dairy Sci. 93:624627.

Ceciliani, F., J. J. Ceron, P. D. Eckersall, and H. Sauerwein. 2012. Acute phase proteins in ruminants. J. Proteomics 75:4207-4231.

Chenault, J. R., J. F. McAllister, S. T. Chester Jr., K. J. Dame, F. M. Kausche, and E. J. Robb. 2004. Efficacy of ceftiofur hydrochloride sterile suspension administered parenterally for the treatment of acute postpartum metritis in dairy cows. J. Am. Vet. Med. Assoc. 224:1634-1639.

CVMP (Committee for Medicinal Products for Veterinary Use). 2009. Revised reflection paper on the use of 3rd and 4th generation cephalosporins in food producing animals in the European Union: Development of resistance and impact on human and animal health. Accessed Jun. 24, 2014. http://www.ema.europa.eu/docs/en_GB/ document_library/Scientific_guideline/2009/10/WC500004307. pdf.

Dalhoff, A., P. G. Ambrose, and J. W. Mouton. 2009. A long journey from minimum inhibitory concentration testing to clinically predictive breakpoints: Deterministic and probabilistic approaches in deriving breakpoints. Infection 37:296-305.

de Boer, M. W., S. J. LeBlanc, J. Dubuc, S. Meier, W. Heuwieser, S. Arlt, R. O. Gilbert, and S. McDougall. 2014. Invited review: Systematic review of diagnostic tests for reproductive-tract infection and inflammation in dairy cows. J. Dairy Sci. 97:3983-3999.

Dolejska, M., Z. Jurcickova, I. Literak, L. Pokludova, J. Bures, A. Hera, L. Kohoutova, J. Smola, and A. Cizek. 2011. IncN plasmids carrying bla CTX-M-1 in Escherichia coli isolates on a dairy farm. Vet. Microbiol. 149:513-516.

Drillich, M., O. Beetz, A. Pfutzner, M. Sabin, H. J. Sabin, P. Kutzer, H. Nattermann, and W. Heuwieser. 2001. Evaluation of a systemic antibiotic treatment of toxic puerperal metritis in dairy cows. J. Dairy Sci. 84:2010-2017.

Drillich, M., D. Voigt, D. Forderung, and W. Heuwieser. 2007. Treatment of acute puerperal metritis with flunixin meglumine in addition to antibiotic treatment. J. Dairy Sci. 90:3758-3763.

Dubuc, J., T. F. Duffield, K. E. Leslie, J. S. Walton, and S. J. LeBlanc. 2010. Definitions and diagnosis of postpartum endometritis in dairy cows. J. Dairy Sci. 93:5225-5233.

Dubuc, J., T. F. Duffield, K. E. Leslie, J. S. Walton, and S. J. LeBlanc. 2011. Randomized clinical trial of antibiotic and prostaglandin treatments for uterine health and reproductive performance in dairy cows. J. Dairy Sci. 94:1325-1338.

Eisend, M. 2004. Metaanalyse-einführung und kritische Diskussion. Page 44 in Wirtschaftswissenschaft. Freie Universität Berlin, Berlin, Germany.

Fishman, N. 2006. Antimicrobial stewardship. Am. J. Infect. Contr. 34:S55-63; discussion S64-73.

Földi, J., M. Kulcsar, A. Pecsi, B. Huyghe, C. de Sa, J. A. Lohuis, P. Cox, and G. Huszenicza. 2006. Bacterial complications of postpartum uterine involution in cattle. Anim. Reprod. Sci. 96:265-281.

Galvão, K. N., L. F. Greco, J. M. Vilela, M. F. Sa Filho, and J. E. Santos. 2009. Effect of intrauterine infusion of ceftiofur on uterine health and fertility in dairy cows. J. Dairy Sci. 92:1532-1542.

Giuliodori, M. J., R. P. Magnasco, D. Becu-Villalobos, I. M. LacauMengido, C. A. Risco, and R. L. de la Sota. 2013. Metritis in dairy cows: Risk factors and reproductive performance. J. Dairy Sci. 96:3621-3631.

Glasziou, P., G. H. Guyatt, A. L. Dans, L. F. Dans, S. Straus, and D. L. Sackett. 1998. Applying the results of trials and systematic reviews to individual patients. ACP J. Club 129:A15-A16.

Gordon, J. L., S. J. LeBlanc, and T. F. Duffield. 2013. Ketosis treatment in lactating dairy cattle. Vet. Clin. North Am. Food Anim. Pract. 29:433-445. 
Goshen, T., and N. Y. Shpigel. 2006. Evaluation of intrauterine antibiotic treatment of clinical metritis and retained fetal membranes in dairy cows. Theriogenology 66:2210-2218.

Haimerl, P., S. Arlt, and W. Heuwieser. 2012. Evidence-based medicine: Quality and comparability of clinical trials investigating the efficacy of prostaglandin $\mathrm{F}(2 \alpha)$ for the treatment of bovine endometritis. J. Dairy Res. 79:287-296.

Haimerl, P., W. Heuwieser, and S. Arlt. 2013. Therapy of bovine endometritis with prostaglandin $\mathrm{F}_{2 \alpha}$ : A meta-analysis. J. Dairy Sci 96:2973-2987.

Hirvonen, J., G. Huszenicza, M. Kulcsar, and S. Pyorala. 1999. Acutephase response in dairy cows with acute postpartum metritis. Theriogenology 51:1071-1083.

Holmes, M., and P. Cockcroft. 2004. Evidence-based veterinary medicine 1. Why is it important and what skills are needed? In Pract. $26: 28-33$.

Humblet, M. F., H. Guyot, B. Boudry, F. Mbayahi, C. Hanzen, F. Rollin, and J. M. Godeau. 2006. Relationship between haptoglobin, serum amyloid A, and clinical status in a survey of dairy herds during a 6-month period. Vet. Clin. Pathol. 35:188-193.

Huzzey, J. M., T. F. Duffield, S. J. LeBlanc, D. M. Veira, D. M. Weary, and M. A. von Keyserlingk. 2009. Short communication: Haptoglobin as an early indicator of metritis. J. Dairy Sci. 92:621-625.

Jeremejeva, J., T. Orro, M. Valdmann, and K. Kask. 2010. Bacteriological and cytological findings during the late puerperal period after two different treatments of retained placenta followed by acute puerperal metritis. Acta Vet. Scand. 52:41.

Jeremejeva, J., T. Orro, A. Waldmann, and K. Kask. 2012. Treatment of dairy cows with $\mathrm{PGF}_{2 \alpha}$ or NSAID, in combination with antibiotics, in cases of postpartum uterine inflammation. Acta Vet. Scand. 54:45.

Jorgensen, J. H., and M. J. Ferraro. 2009. Antimicrobial susceptibility testing: A review of general principles and contemporary practices. Clin. Infect. Dis. 49:1749-1755.

Kalmus, P., H. Simojoki, T. Orro, S. Taponen, K. Mustonen, J. Holopainen, and S. Pyorala. 2014. Efficacy of 5-day parenteral versus intramammary benzylpenicillin for treatment of clinical mastitis caused by gram-positive bacteria susceptible to penicillin in vitro. J. Dairy Sci. 97:2155-2164.

Kaneene, J. B., P. H. Coe, J. H. Smith, P. Rapnicki, C. L. Smith, B. Gerloff, and D. A. Morrow. 1986. Drug residues in milk after intrauterine injection of oxytetracycline, lincomycin-spectinomycin, and povidone-iodine in cows with metritis. Am. J. Vet. Res. 47:1363-1365.

Karger, S., S. Arlt, P. Haimerl, and W. Heuwieser. 2014. A systematic review of studies performing the hypo-osmotic swelling test to evaluate the quality of canine spermatozoa. Reprod. Domest. Anim. 49:1-6.

Kastelic, J. P. 2006. Critical evaluation of scientific articles and other sources of information: An introduction to evidence-based veterinary medicine. Theriogenology 66:534-542.

Lehtopolku, M., P. Kotilainen, P. Puukka, U. M. Nakari, A. Siitonen, E. Eerola, P. Huovinen, and A. J. Hakanen. 2012. Inaccuracy of the disk diffusion method compared with the agar dilution method for susceptibility testing of Campylobacter spp. J. Clin. Microbiol. $50: 52-56$.

Lexchin, J., L. A. Bero, B. Djulbegovic, and O. Clark. 2003. Pharmaceutical industry sponsorship and research outcome and quality: Systematic review. BMJ 326:1167-1170.

Lima, F. S., A. Vieira-Neto, G. S. Vasconcellos, R. D. Mingoti, E. Karakaya, E. Sole, R. S. Bisinotto, N. Martinez, C. A. Risco, K. N. Galvão, and J. E. Santos. 2014. Efficacy of ampicillin trihydrate or ceftiofur hydrochloride for treatment of metritis and subsequent fertility in dairy cows. J. Dairy Sci. 97:5401-5414.

Machado, V. S., M. L. Bicalho, E. B. Meira Junior, R. Rossi, B. L. Ribeiro, S. Lima, T. Santos, A. Kussler, C. Foditsch, E. K. Ganda, G. Oikonomou, S. H. Cheong, R. O. Gilbert, and R. C. Bicalho. 2014. Subcutaneous immunization with inactivated bacterial components and purified protein of Escherichia coli, Fusobacterium necrophorum and Trueperella pyogenes prevents puerperal metritis in Holstein dairy cows. PLoS ONE 9:e91734.
Machado, V. S., M. L. Bicalho, R. V. Pereira, L. S. Caixeta, J. H. Bittar, G. Oikonomou, R. O. Gilbert, and R. C. Bicalho. 2012. The effect of intrauterine administration of mannose or bacteriophage on uterine health and fertility of dairy cows with special focus on Escherichia coli and Arcanobacterium pyogenes. J. Dairy Sci. 95:3100-3109.

Malinowski, E., H. Lassa, H. Markiewicz, M. Kaptur, M. Nadolny, W. Niewitecki, and J. Zietara. 2011. Sensitivity to antibiotics of $A r$ canobacterium pyogenes and Escherichia coli from the uteri of cows with metritis/endometritis. Vet. J. 187:234-238.

Mann, S., J. D. Siler, D. Jordan, and L. D. Warnick. 2011. Antimicrobial susceptibility of fecal Escherichia coli isolates in dairy cows following systemic treatment with ceftiofur or penicillin. Foodborne Pathog. Dis. 8:861-867.

Markusfeld, O. 1987. Periparturient traits in seven high dairy herds. Incidence rates, association with parity, and interrelationships among traits. J. Dairy Sci. 70:158-166.

McKenna, M. 2013. Antibiotic resistance: The last resort. Nature 499:394-396.

McLaughlin, C. L., E. Stanisiewski, M. J. Lucas, C. P. Cornell, J. Watkins, L. Bryson, J. K. S. Tena, J. Hallberg, and J. R. Chenault 2012. Evaluation of two doses of ceftiofur crystalline free acid sterile suspension for treatment of metritis in lactating dairy cows. J. Dairy Sci. 95:4363-4371.

McLaughlin, C. L., E. P. Stanisiewski, C. A. Risco, J. E. Santos, G E. Dahl, R. C. Chebel, C. LaGrow, C. Daugherty, L. Bryson, D Weigel, J. Hallberg, and M. J. Lucas. 2013. Evaluation of ceftiofur crystalline free acid sterile suspension for control of metritis in high-risk lactating dairy cows. Theriogenology 79:725-734.

Miller, A. N., E. J. Williams, K. Sibley, S. Herath, E. A. Lane, J. Fishwick, D. M. Nash, A. N. Rycroft, H. Dobson, C. E. Bryant, and I. M. Sheldon. 2007. The effects of Arcanobacterium pyogenes on endometrial function in vitro, and on uterine and ovarian function in vivo. Theriogenology 68:972-980.

Moore, C. W., J. J. Marnewick, and A. C. Henning. 1984. On the use of oxytetracycline in reducing the incidence of metritis in dairy cows. J. S. Afr. Vet. Assoc. 55:65-69.

Nak, Y., S. B. Dagalp, C. Cetin, D. Nak, F. Alkan, E. Borum, and B. Tuna. 2011. Course and severity of postpartum metritis cases following antibiotic and $\mathrm{PGF}_{2 \alpha}$ administration in postpartum metritis cows infected with BoHV-4. Transbound. Emerg. Dis. 58:31-36.

Nault, A. J., and H. J. Baker. 2011. The power of information. J. Vet Med. Educ. 38:3-4.

Noakes, D. E., L. Wallace, and G. R. Smith. 1991. Bacterial flora of the uterus of cows after calving on two hygienically contrasting farms. Vet. Rec. 128:440-442.

Okike, K., M. S. Kocher, C. T. Mehlman, and M. Bhandari. 2008. Industry-sponsored research. Injury 39:666-680.

Olivry, T., and R. S. Mueller. 2003. Evidence-based veterinary dermatology: A systematic review of the pharmacotherapy of canine atopic dermatitis. Vet. Dermatol. 14:121-146.

Overton, M., and J. Fetrow. 2008. Economics of postpartum uterine health. Pages 39-44 in Proc. Dairy Cattle Reproduction Council Conv., Omaha, NE. Dairy Cattle Reproduction Council, Champaign, IL.

Ozawa, T., Y. Kiku, M. Mizuno, S. Inumaru, S. Kushibiki, H. Shingu, T. Matsubara, H. Takahashi, and T. Hayashi. 2012. Effect of intramammary infusion of rbGM-CSF on SCC and expression of polymorphonuclear neutrophil adhesion molecules in subclinical mastitis cows. Vet. Res. Commun. 36:21-27.

Palenik, T., R. Dolezel, J. Kratochvil, S. Cech, J. Zajic, Z. Jan, and M. Vyskocil. 2009. Evaluation of rectal temperature in diagnosis of puerperal metritis in dairy cows . Vet. Med. Czech. 54:149-155.

Pierce-Hendry, S. A., and J. Dennis. 2010. Bacterial culture and antibiotic susceptibility testing. Compend. Contin. Educ. Vet. 32:E15; quiz E6.

Plaizier, J. C., K. D. Lissemore, D. Kelton, and G. J. King. 1998 Evaluation of overall reproductive performance of dairy herds. J. Dairy Sci. 81:1848-1854.

Risco, C. A., and J. Hernandez. 2003. Comparison of ceftiofur hydrochloride and estradiol cypionate for metritis prevention and re- 
productive performance in dairy cows affected with retained fetal membranes. Theriogenology 60:47-58.

Rocksin, A., G. F. Gerlach, and S. Schwarz. 2007. [The implementation of the broth microdilution method to determine bacterial susceptibility to antimicrobial agents]. Berl. Munch. Tierarztl. Wochenschr. 120:42-49.

Sannmann, I., S. Arlt, and W. Heuwieser. 2012. A critical evaluation of diagnostic methods used to identify dairy cows with acute postpartum metritis in the current literature. J. Dairy Res. 79:436444.

Sannmann, I., O. Burfeind, V. Suthar, A. Bos, M. Bruins, and W. Heuwieser. 2013a. Technical note: Evaluation of odor from vaginal discharge of cows in the first 10 days after calving by olfactory cognition and an electronic device. J. Dairy Sci. 96:5773-5779.

Sannmann, I., O. Burfeind, R. Voigtsberger, and W. Heuwieser. 2013b. Comparison of two monitoring and treatment strategies for cows with acute puerperal metritis. Theriogenology 79:961-969.

Santos, T. M., R. O. Gilbert, and R. C. Bicalho. 2011. Metagenomic analysis of the uterine bacterial microbiota in healthy and metritic postpartum dairy cows. J. Dairy Sci. 94:291-302.

Sargeant, J. M., A. Rajic, S. Read, and A. Ohlsson. 2006. The process of systematic review and its application in agri-food public-health. Prev. Vet. Med. 75:141-151.

Sawant, A. A., L. M. Sordillo, and B. M. Jayarao. 2005. A survey on antibiotic usage in dairy herds in Pennsylvania. J. Dairy Sci. 88:2991-2999.

Sheldon, I. M., M. Bushnell, J. Montgomery, and A. N. Rycroft. 2004. Minimum inhibitory concentrations of some antimicrobial drugs against bacteria causing uterine infections in cattle. Vet. Rec. 155:383-387.

Sheldon, I. M., J. Cronin, L. Goetze, G. Donofrio, and H.-J. Schuberth. 2009. Defining postpartum uterine disease and the mechanisms of infection and immunity in the female reproductive tract in cattle. Biol. Reprod. 81:1025-1032.

Sheldon, I. M., G. S. Lewis, S. LeBlanc, and R. O. Gilbert. 2006. Defining postpartum uterine disease in cattle. Theriogenology 65:1516-1530.

Sheldon, I. M., D. E. Noakes, A. Rycroft, and H. Dobson. 2001. Acute phase protein responses to uterine bacterial contamination in cattle after calving. Vet. Rec. 148:172-175.

Sheldon, I. M., E. J. Williams, A. N. A. Miller, D. M. Nash, and S. Herath. 2008. Uterine diseases in cattle after parturition. Vet. J. 176:115-121.

Silverlås, C., C. Bjorkman, and A. Egenvall. 2009. Systematic review and meta-analyses of the effects of halofuginone against calf cryptosporidiosis. Prev. Vet. Med. 91:73-84.

Silvestre, F. T., T. S. Carvalho, N. Francisco, J. E. Santos, C. R. Staples, T. C. Jenkins, and W. W. Thatcher. 2011. Effects of differential supplementation of fatty acids during the peripartum and breeding periods of Holstein cows: I. Uterine and metabolic responses, reproduction, and lactation. J. Dairy Sci. 94:189-204.

Simoneit, C., W. Heuwieser, and S. Arlt. 2012. [Evidence based medicine in veterinary daily practice]. Tierarztl. Prax. Ausg. G Grosstiere Nutztiere 40:186-192. (Article in German)

Smith, B. I., G. A. Donovan, C. Risco, R. Littell, C. Young, L. H. Stanker, and J. Elliott. 1998a. Comparison of various antibiotic treatments for cows diagnosed with toxic puerperal metritis. J. Dairy Sci. 81:1555-1562.

Smith, B. I., G. A. Donovan, C. A. Risco, C. R. Young, and L. H. Stanker. 1998b. Serum haptoglobin concentrations in Holstein dairy cattle with toxic puerperal metritis. Vet. Rec. 142:83-85.

Smith, R. 1996. What clinical information do doctors need? BMJ 313:1062-1068.

Steffan, J., M. Agric, S. Adriamanga, and M. Thibier. 1984. Treatment of metritis with antibiotics or prostaglandin F2 alpha and influence of ovarian cyclicity in dairy cows. Am. J. Vet. Res. 45:1090-1094.

Supré, K., K. Lommelen, and L. De Meulemeester. 2014. Antimicrobial susceptibility and distribution of inhibition zone diameters of bovine mastitis pathogens in Flanders, Belgium. Vet. Microbiol. 171:374-381.

Teale, C. J., and G. Moulin. 2012. Prudent use guidelines: A review of existing veterinary guidelines. Rev. Sci. Tech. 31:343-354.

Tragesser, L. A., T. E. Wittum, J. A. Funk, P. L. Winokur, and P. J. Rajala-Schultz. 2006. Association between ceftiofur use and isolation of Escherichia coli with reduced susceptibility to ceftriaxone from fecal samples of dairy cows. Am. J. Vet. Res. 67:1696-1700.

van Knegsel, A. T. S. G. van der Drift, J. Cermakova, and B. Kemp. 2013. Effects of shortening the dry period of dairy cows on milk production, energy balance, health, and fertility: A systematic review. Vet. J. 198:707-713.

Vandeweerd, J. M., P. Clegg, V. Hougardy, and S. Buczinski. 2012. Using systematic reviews to critically appraise the scientific information for the bovine veterinarian. Vet. Clin. North Am. Food Anim. Pract. 28:13-21, vii.

von Krueger, X., P. Scherpenisse, S. Roiger, and W. Heuwieser. 2013. Determination of ceftiofur derivatives in serum, endometrial tissue, and lochia in puerperal dairy cows with fever or acute puerperal metritis after subcutaneous administration of ceftiofur crystalline free acid. J. Dairy Sci. 96:1054-1062.

Watson, P. F., and A. Petrie. 2010. Method agreement analysis: A review of correct methodology. Theriogenology 73:1167-1179.

Witte, T. S., M. Iwersen, T. Kaufmann, P. Scherpenisse, A. A. Bergwerff, and W. Heuwieser. 2011. Determination of ceftiofur derivatives in serum, endometrial tissue, and lochia in puerperal dairy cows after subcutaneous administration of ceftiofur crystalline free acid. J. Dairy Sci. 94:284-290. 